\title{
Shielding Effectiveness Measurements of Coaxial Cable and Connectors Using Compact Open Area Test Site
}

\author{
Kenedy Marconi G. Santos ${ }^{1,2}$ *, Marcela Silva Novo ${ }^{2}$, Glauco Fontgalland ${ }^{3}$ \\ Marcelo Bender Perotoni ${ }^{4}$ and Caio Luminatti Andrade \\ IFBA ${ }^{1}$-Federal Institute of Bahia, Av. Amazonas, 3150, Vitória da Conquista, Brazil \\ UFBA $^{2}$-Federal University of Bahia, R. Aristides Novis, 02 Salvador, Brazil \\ UFCG $^{3}$-Federal University of Campina Grande, R.Aprígio Veloso, 882, Campina Grande, Brazil \\ $\mathrm{UFABC}^{4}$ - Federal University of ABC, R. Abolição, s/n ${ }^{\circ}$, Santo Andre, Brazil \\ *kenedymarconi@gmail.com,
}

\begin{abstract}
This article presents a set of measurements and simulations that evaluate the technical feasibility of a Compact Open Area Test Site (COATS), for the frequency range of $200 \mathrm{MHz}$ to $2 \mathrm{GHz}$. Its main goal is to provide shielding effectiveness measurements. The described test setup is used for the tests in both semi anechoic chamber and COATS. These experimental and computational results offer orientations and guidelines about the best method to measure radiated emission in a COATS. These measurements results can be quantified through the Feature Selective Validation technique.
\end{abstract}

\section{INTRODUCTION}

Nowadays the use of mobile information technology equipment at home, in the office, or in vehicles like cars, planes and trains has increased significantly. Indeed, electronic systems are fundamental to improve comfort, entertainment, reliability and security for the users. In spite of all the evident benefits and simplifications brought about by these systems, electromagnetic noise is always present in the environment and affects the normal operation of the wireless channels.

The shielding effectiveness parameter of a coaxial cable is a relevant parameter for ensuring electromagnetic compatibility with adjacent electronic systems [1,2], providing an adequate shielding against the environment. In this context, the study of shielded cables is important for the mitigation of these problems. With this in mind, one way to increase immunity and reduce the radiated electromagnetic noise is to improve the transmission line characteristics, i.e. apply shielding techniques [3,4]. Several international standards suggest methodologies to assess the functioning of embedded electronics and information technology, establishing various test procedures and defining reference levels for radiated electromagnetic fields $[5,6]$. Therefore, developed products must meet current regulations before they are sold. Though necessary, the high costs associated to electromagnetic compatibility (EMC) tests sometimes become a problem, since they must be performed in accredited laboratories. Locally, in Brazil for instance, the body that is a signatory to ILAC (International Laboratory Accreditation Cooperation) and which regulates and accredits these laboratories is the National Institute of Metrology, Standardization and Industrial Quality 
(INMETRO). The cost of an EMC laboratory equipped with precision equipment for automotive tests, with dynamometer roll and a large semi-anechoic chamber (SAC) can reach several million dollars. In Brazil there are currently no EMC laboratories able to meet $100 \%$ of the national automotive industry demand, to quote a specific area. In this work we will investigate the technical feasibility of building an open area test site (OATS) to measure the quality factor of the shielded cables and connectors in the frequency range of $200 \mathrm{MHz}$ to $2 \mathrm{GHz}$.

An experimental investigation with the objective of measuring the quality of the shielding effectiveness of coaxial cable and connectors in the UHF band will be performed. In this context it is necessary to perform various measurements and studies in order to verify if the amplitude of the electromagnetic field levels in the environment meets the current regulations [6,7]. The site chosen for the research is a farm near the city of Capelinha, Minas Gerais, Brazil (Lat. 17,8651 ${ }^{\circ} \mathrm{S}-$ Long. $42,4313^{\circ} \mathrm{W}$ ). Considering that the OATS is properly constructed, some of the great advantages of open field tests compared with anechoic and semi-anechoic chambers are the low cost of measurements (one-time costs of about five-hundred thousand Dollars) and the ability to obtain accurate measurements [8]. Table I show some latest relevant papers (on the OATS subject) published in the databases of the IEEE during 2013-2017

Table 1 Articles published in the databases of the IEEE

\begin{tabular}{l|c|c}
\hline \multicolumn{1}{c|}{ Title } & Publication & Reference \\
\hline $\begin{array}{l}\text { A Phase-Matching Method for Antenna Phase Center Determination Basing } \\
\text { upon Site Insertion Loss Measurement in OATS }\end{array}$ & Oct. 2013 & {$[9]$} \\
\hline Analysis of Scattering Property of Open-Area Test Site Ground Plane & Aug. 2014 & {$[10]$} \\
\hline On the Quality of a Real Open Area Test Site & Aug. 2015 & {$[11]$} \\
\hline $\begin{array}{l}\text { Research on Unwanted Reflections in an OATS for Precise Omni Antenna } \\
\text { Measurement }\end{array}$ & Oct. 2015 & {$[12]$} \\
\hline $\begin{array}{l}\text { The Use of Equivalent Model and Numerical Simulation for EMC Analysis } \\
\text { in Hospital Environments }\end{array}$ & Aug. 2016 & {$[13]$} \\
\hline A Fast Way to Accurately Calibrate Tunable Dipole Antennas at VHF & Jun. 2017 & {$[14]$} \\
\hline
\end{tabular}

The article [9] focuses on the phase center determination for broadband wire-element EMC antenna. A novel technique called phase-matching is proposed, which uses measurement data of insertion loss between an antenna under test and a reference antenna, the latter with a known phase center. This setup takes place in an open area test site. The typical error is estimated to be about $60 \mathrm{~mm}$ around $250 \mathrm{MHz}$, and is reduced to $15 \mathrm{~mm}$ around $900 \mathrm{MHz}$.

The next publication [10] has given a comprehensive analysis on a real OATS scattering property. The effect shows that the a given ground at X-band has a solid backward scattering at the positions of slits and bolts. The effect of a reported experiment has been the backward scattering reduction due to the slits.

The article "On the Quality of a Real Open Area Test Site" [11], shows that physical open area test site performance is affected by various factors, e.g., practical elements antennas, the power supply 
quality, the electric properties of the ground and surrounding scattering sources. The authors employed computer simulations to quantitatively define the effect of all influences that make a real test site diverge from an ideal one-

The paper "Research on Unwanted Reflections in an OATS for Precise Omni Antenna Measurement" [12] shows that reflections from the trees nearby and from the edge of the metal ground plane of an OATS bring imprecisions to omni-directional antenna measurements from $20 \mathrm{MHz}$ To $1 \mathrm{GHz}$. However, the research also shows that reflections are very hard to accurately address, given the intricate rigorous theory concerning the relationship between the reflections and the configurations of an OATS.

The work "The Use of Equivalent Model and Numerical Simulation for EMC Analysis in Hospital Environments" [13] promotes the use of prediction methods as an alternative tool for evaluating and managing electromagnetic compatibility (EMC) in hospital environments. Radiated emissions made from medical apparatus are modelled based on open area test site measurements, and they are useful to numerical simulation using the transmission line matrix method (TLM). The TLM method is implemented to cover not only the multipath effects caused by obstacles but also the combination of all diverse sources on the environment under test [13].

In the reference [14] a fast technique is proposed and experimentally confirmed to adjust tunable dipole antennas. An adapter is introduced to transform a commercially available balun for dipoles into a three-port network. Additionally, the three-port balun technique is suggested to measure the loss of another balun with two simple adapters, which delivers a quicker method to calculate the free-space antenna factor. The new technique will diminish the time from numerous days to some hours to regulate a pair of tunable dipole antennas.

\section{PROBLEM FORMULATION}

The procedures used in an Open Area Test Site (OATS) to measure the radiated electromagnetic fields of a device under test (DUT) are similar to those in a semi-anechoic chamber (SAC). In order to ensure the quality of measurements in a SAC and OATS, it is important to measure the electromagnetic ambient noise in the frequency bands defined by the radiated emissions standards. Since the OATS operates in free space, without the shielding of metallic walls covered with electromagnetic absorber, this study is of paramount importance and gives the indication whether the area can be used as an OATS or not. Thus it is possible to know the environmental contribution and isolate the contribution of the signal to be measured.

The procedures required to normalize the local levels of attenuation (Normalized Site Attenuation NSA) and measure the levels of radio frequency signals as environmental conditions are presented in CISPR 16-1-4 [7]. The NSA has become an internationally used parameter for determining the acceptability of a site for performing open area tests with focus on performing electromagnetic emission measurements [7]. The levels of ambient radio frequency signals in the environment, i.e., the 
background electromagnetic noise at the test site must be sufficiently small in comparison with the levels of electromagnetic noise generated by the DUT. The electromagnetic ambient noise should be at least $6 \mathrm{~dB}$ below the limits set by radiated emissions standards [5, 6]. For satisfactory results, it is recommended a level of ambient noise of $20 \mathrm{~dB}$ below the emission level measured [7, 8]. The radiated electromagnetic emission tests were carried out in the far-field region. The site chosen was the farm parking lot area in a region of low amplitude electromagnetic signals (a valley embedded in a mountain area). In Fig. 1 it is shown where measurements have been performed and the ETS 3148 log periodic antenna which operates in the frequency range of $200 \mathrm{MHz}$ to $2 \mathrm{GHz}$. The farm house is surrounded by mountains and has considerable electromagnetic silence in this frequency range.

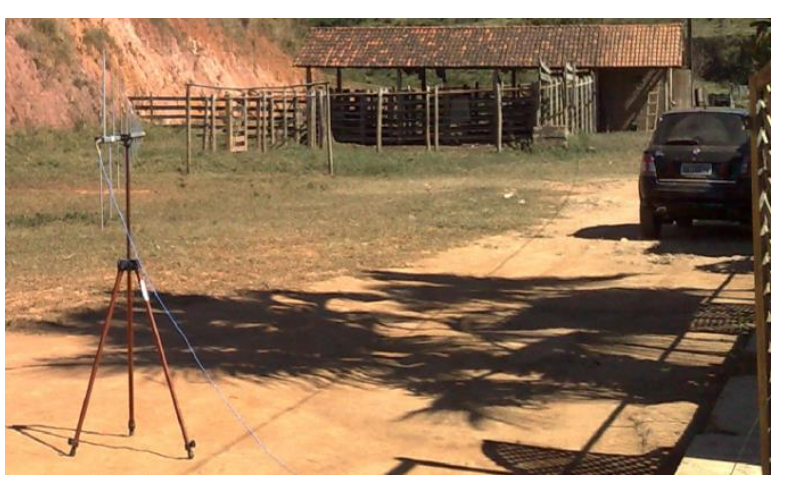

$a$

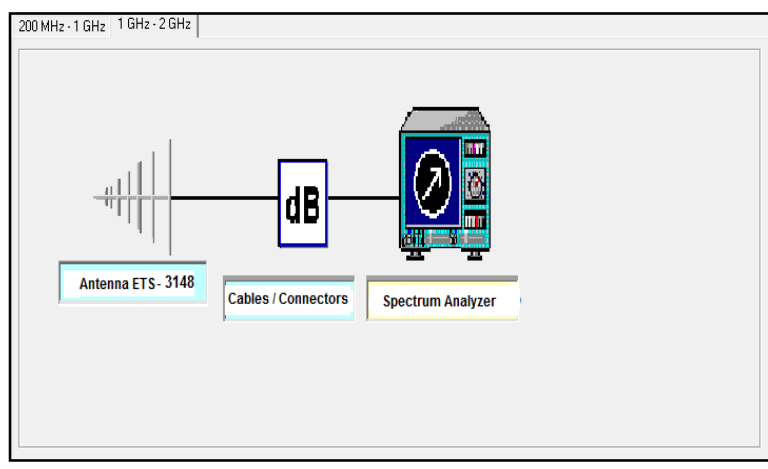

$c$

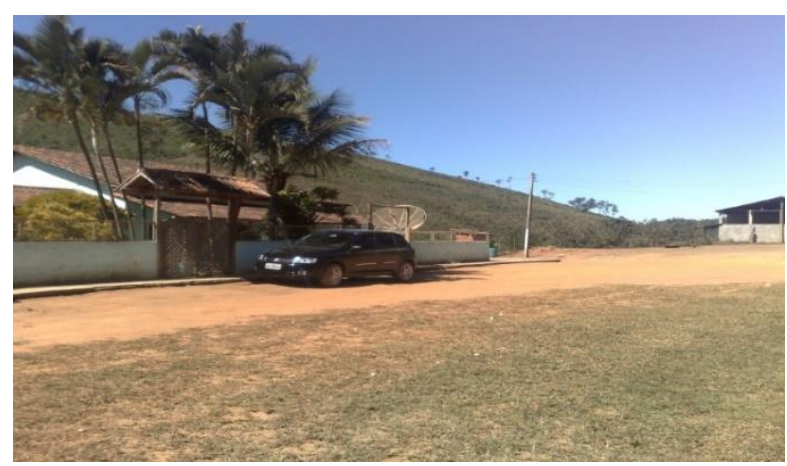

$b$

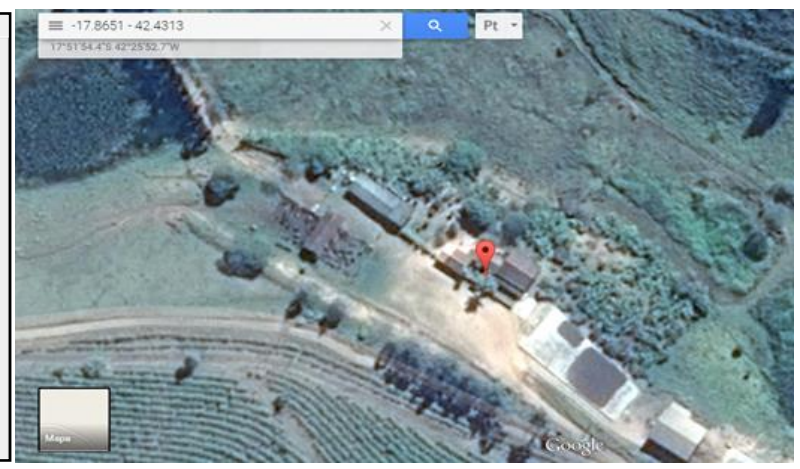

$d$

Fig. 1. Log-Periodic Dipole Array Antenna, the parking near the city of Capelinha, aerial photograph and the setup used: (a) Antenna-3148; (b) Parking located at Lat. 17.8651 ${ }^{\circ} \mathrm{S}$ Long. $42.4313^{\circ} \mathrm{W}$; (c) Setup used to measure the electromagnetic noise in open area; $(d)$ Farm located near the city of Capelinha, state Minas Gerais, Brazil (Lat.17,8651 ${ }^{\circ}$ - Long. $42,4313^{\circ} \mathrm{W}$ ) [Reference source: Google maps]

During the measurements, it was not possible to capture electromagnetic signals from local mobile phone providers. Fig. 1c shows the arrangement used for the measurement of electromagnetic ambient noise, in a block diagram format, and Fig. 1d an aerial photograph of the test site. When tuning a car receiver, we observed the presence of a medium wave transmission with amplitude modulated signals in the frequency of $610 \mathrm{kHz}$ - Itatiaia AM radio station. In the VHF band- signals from FM radios from 88 to $108 \mathrm{MHz}$ it was only possible to tune the frequency of $105.3 \mathrm{MHz}$ - the Aranãs FM radio station, located close to Capelinha city - MG. The TV reception at the farm is only possible through the use of a satellite dish. Consequently, it can be inferred that, in this region, no analog TV signal is 
available in VHF and UHF band (although digital TV arrival can modify this silent ambient in the next years, covering a higher frequency range, above $470 \mathrm{MHz}$ ). Measurements have been performed in vertical and horizontal polarization considering four directions: North, South, East and West, with angular variations of $0^{\circ}, 90^{\circ}, 180^{\circ}$ and $270^{\circ}$. Amplitude limits adopted for the measured signal have been chosen according to CISPR22 and CISPR25 standards $[5,6]$.

\section{RESULTS OF MEASUREMENTS}

The measurements in horizontal polarization are presented in Figures 2 and 3. The vertical polarization measurements showed lower amplitudes and are not presented in this paper. The antenna factor AF of the ETS $3148 \log$ periodic is defined as the ratio of the incident electric field at the surface of the measurement antenna (defined in equation 1) over the received voltage at the antenna terminals [1]. This data is provided by the manufacturer.

$$
A F(d B)=\frac{d B \mu V}{m}(\text { incident_field })-d B \mu V(\text { received_voltage })
$$

Figure 2 shows the electromagnetic noise measured in the OATS. Measurements have been made from $200 \mathrm{MHz}$ to $1 \mathrm{GHz}$ in the horizontal polarization $-0^{\circ}, 90^{\circ}, 180^{\circ}$ and 270 degrees. The limit lines have been established according to CISPR22 standard (using the QPK value- quasi peak). All measurements related to electromagnetic ambient noise show that the amplitudes of the noise are 20 $\mathrm{dB}$ below the measurement levels for class A Information Technology Equipment (ITE) and $6 \mathrm{~dB}$ below for class B (ITE) [5]. For impeccable results, an ambient noise level of $20 \mathrm{~dB}$ below the emission level measured is recommended [8, 15]. Class B Information Technology Equipment (ITE) is a category of apparatus which satisfies the class B disturbance limits. This device is intended predominantly for use in the domestic environment and may include appliances with no fixed place. Examples of Class B would be portable equipment powered by batteries, telecommunication terminal devices powered by a telecommunication network and personal computers. Class A Information Technology Equipment is a category for all other devices which satisfies the class A limits but not the class B ITE boundaries.

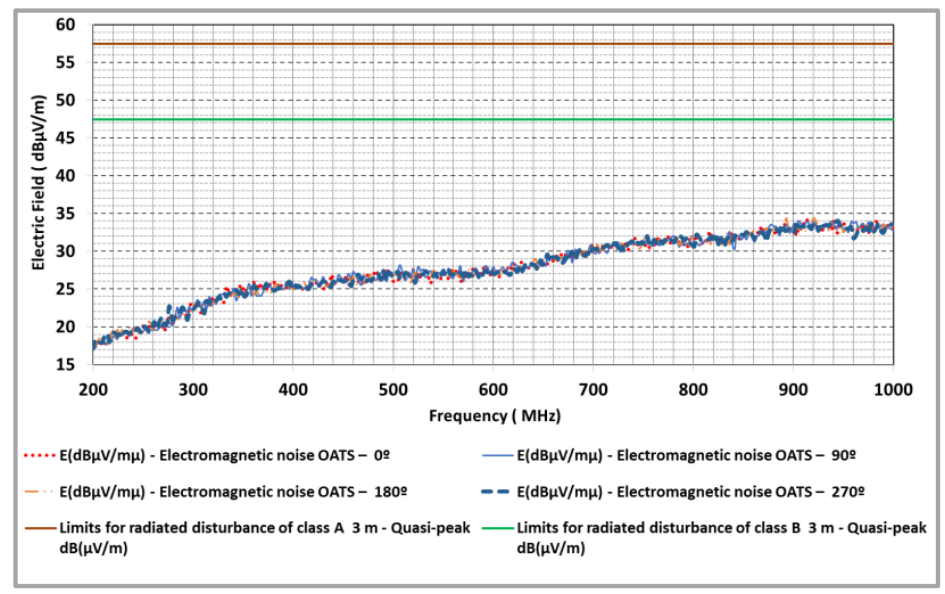

Fig. 2. Electromagnetic noise OATS $-0^{\circ}, 90^{\circ}, 180^{\circ}$ and $270^{\circ}$ horizontal polarization and UHF 
Figure 2 shows that there are no significant changes in the electric field at positions $0^{\circ}, 90^{\circ}, 180^{\circ}$ and 270 degrees. The graph in the Figure 3 shows the electromagnetic noise in the frequency domain measured in the horizontal polarization - $0^{\circ}$ degrees. The limit line of the CISPR 25 standard was used in the frequency range from $1 \mathrm{GHz}$ to $2 \mathrm{GHz}$.

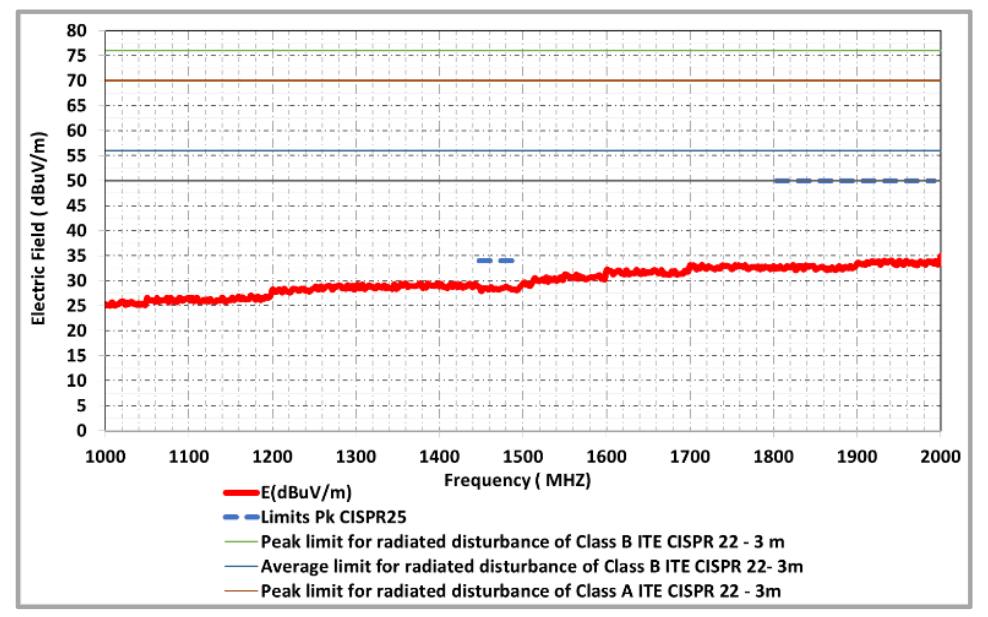

Fig. 3. Electromagnetic noise OATS - $0^{\circ}$ horizontal polarization UHF:

$1 \mathrm{GHz}$ to $2 \mathrm{GHz}$ - Limit line by CISPR 25 and CISPR 22

Several measurements have been performed with the spectrum analyzer function set in "max-hold" as to actually record the maximum levels acquired over the acquisition time, capturing the worst case scenario. Only one measurement has been performed in UHF band (the maximum amplitude). In this band, the electromagnetic wave usually provides a more directional characteristic than those at HF and VHF bands.

\section{COMPUTER SIMULATIONS}

The computer modelling has been performed using MWS®-CST [16]. This tool uses the FIT method (Finite Integration Technique) and MoM (method of moments), numerical methods that use a discrete representation of Maxwell's equations for the solution of these integral equations. A simulation model has been created based on a metal ellipse with the largest radius of 6 meters and the smallest radius measuring 5.19 meters. Two similar dipole antennas, resonating at a frequency of $678.7 \mathrm{MHz}$ have been positioned, one set as a transmitter and the other as a receiver. Its length is $0.197 \mathrm{~m}$ and the wire radius is $1 \mathrm{~mm}$. They were positioned to generate a signal in horizontal polarization. Details are shown in the Figures $4 a$ and $4 b$. 


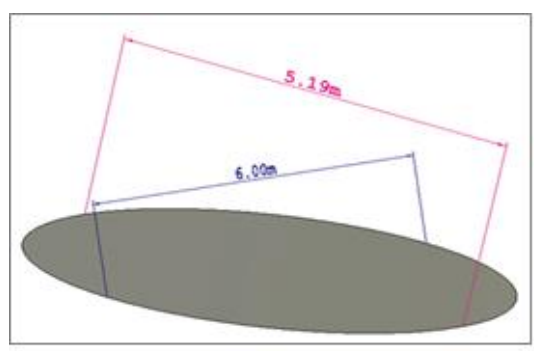

(a)

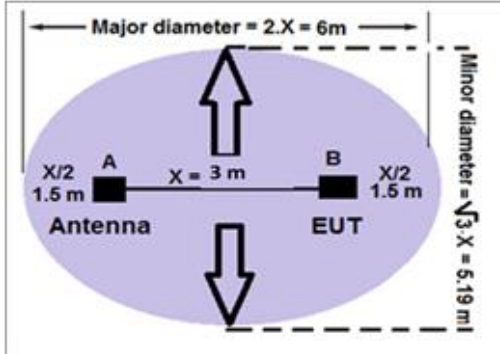

(c)

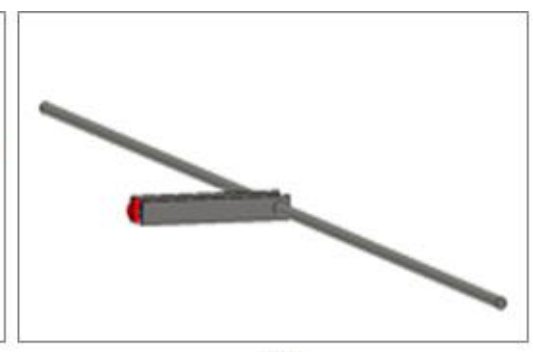

(b)

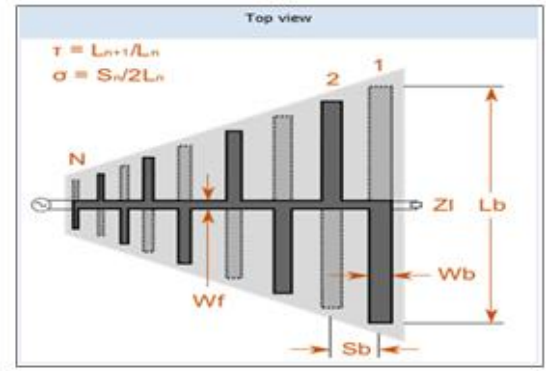

(d)

Fig. 4. Used Simulation model : (a) Metal ellipse representing the OATS; (b) The used dipole antenna model; (c) The top view of the "CISPR ellipse" and the antennas position; (d) Log periodic antenna used in virtual model

The antennas are fed by discrete 50 Ohms impedance ports, which automatically perform the mode conversion that feeds a balanced signal into the antennas. As defined in the literature [7, 17, 18], Figure $4 \mathrm{c}$ shows that the ground plane has the form of an ellipse (named "CISPR Ellipse"), and the antennas are located at the points " $\mathrm{A}$ " and " $\mathrm{B}$ " in the figure. $X$ is the measurement distance between the point $\mathrm{A}$ and $\mathrm{B}$. The ellipse must be free of any reflecting objects on its area. Two configurations have been evaluated using the procedure described in Figure 4c:

1. Receiving antenna 1 meter above the ground plane;

2. Receiving antenna 4 meters above the ground plane.

For both situations the transmitter antenna (two dipoles and two log periodic antennas were used for two different virtual evaluations) was fixed 2 meters above the ground plane. According to the definition given in CISPR-16, the Open Area Site Attenuation (OASA) is defined in equation (2) as:

$$
\text { OASA }=\frac{V_{-} T X}{V_{-} R X}
$$

$V_{T X}$ and $V_{R X}$ are the voltages measured at $50 \Omega$ reference inputs for transmitter and receiver antennas. The parameter Normalized Site Attenuation (NSA) is then defined in equation (3) as:

$$
N S A=\frac{O A S A}{A F_{T X} A F_{R X}}=\frac{V_{T X}}{V_{R X}} \cdot \frac{1}{A F_{T X} A F_{R X}}
$$

$A F_{T X}$ and $A F_{R X}$ are the transmitter and receiver Antenna Factors, respectively.

In the simulation with a ground plane with conductivity of $3.56 \times 10^{6} \mathrm{~S} / \mathrm{m}$, the receiving antennas (dipole and log periodic) are placed at a height of 1 meter above the ground plane, the calculated result is close to the theoretical value [7]. However when the RX antenna is placed at a height of four meters, the amplitude shows a difference bigger than the $+/-4 \mathrm{~dB}$ error margin. Table I presents the 
analytical NSA and computed NSA by the CST MWS® $[16,20]$. CISPR-16 provides an analytical formulation for the Antenna Factor, when the radiant system is a tuned half-wavelength dipole:

$$
A F=20 \log (f)-31.9
$$

Where $f$ is the frequency in MHz. This equation is effective for frequencies close to the resonance (when its input impedance is about 73 Ohms). Table II synthetizes the comparison between the simulated and theoretical NSA values, only for the frequency of $678.7 \mathrm{MHz}$. Theoretical normalized site attenuation provided in CISPR-16 for $600 \mathrm{MHz}$ is $-18.3 \mathrm{~dB}$ and $-19.7 \mathrm{~dB}$ for $700 \mathrm{MHz}$. For the resonance frequency of the antennas of $678.7 \mathrm{MHz}$, an NSA of $-19.4 \mathrm{~dB}$ has been found by straight line interpolation.

Table 2 Comparison of the simulated and theoretical NSA results - half wavelength dipole antenna

\begin{tabular}{llll}
\hline $\begin{array}{l}\text { Theoretical } \\
\text { NSA }(\mathrm{dB}) \text { - CISPR16 }\end{array}$ & $\begin{array}{c}\text { Measured } \\
\text { NSA [dB] }\end{array}$ & $\begin{array}{l}\text { Computed NSA } \\
{[\mathrm{dB}]}\end{array}$ \\
\hline $\begin{array}{l}\text { RX antena } \\
1 \text { meter height }\end{array}$ & -19.4 & -19.39 & -19.1 \\
$\begin{array}{l}\text { RX antenna } \\
4 \text { meters height }\end{array}$ & -19.4 & -19.99 & -7.2 \\
\hline
\end{tabular}

Simulations showed that the RX antenna result when positioned at 4 meters height is not in accordance with the current standard CISPR16, as the norm specifies a maximum difference of $+/-4$ $\mathrm{dB}$ between the simulated value and the Theoretical NSA [7]. During the simulations, the NSA (dB) for RX antenna at 4 meters is $-7.2 \mathrm{~dB}$, the measured is $-19.99 \mathrm{~dB}$ and the theoretical NSA from CISPR16 $(\mathrm{dB})$ is $-19.4 \mathrm{~dB}$. The Fig. $4 \mathrm{~d}$ shows the log periodic antenna used in another simulation model, taken from Antenna Magus software, used as approximate model for the next section.

\section{MEASUREMENTS WITH THE PROPOSED EXPERIMENTAL SETUP}

In order to measure the normalized site attenuation using a vector network analyzer, two antennas were placed over a ground plane $[7,17,18]$. The transmitter (TX) antenna was at two meters from the ground plane whereas the receiving antenna (RX) is placed at height of 1 meter and 4 meters (as in the simulation scenario of the former section). The two log periodic antennas used in the measurements were not identical and also different from the model used in the simulation. Fig. 5a shows that there are differences between the $\mathrm{S} 21$ (equivalent for the transmission loss between the two antennas) for the RX antenna placed at heights of 1 and 4 meters. Fig.5b illustrates the measurement setup. It can be seen that the ground plane has not the ellipsoidal format, and it was performed in an indoor area, subject to reflections from the ceiling and nearby walls. 


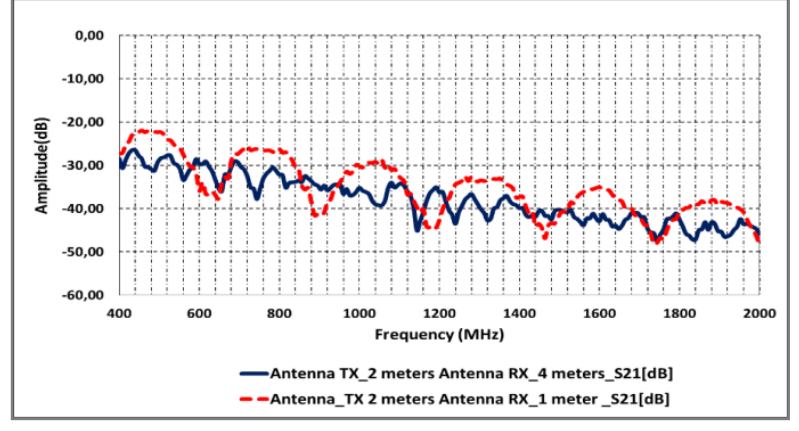

$a$

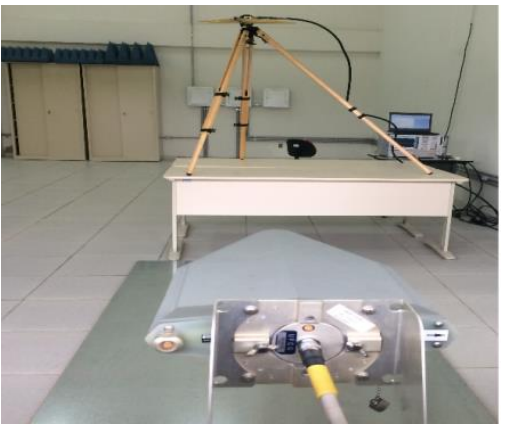

$b$

Fig.5. Log periodic antenna used in virtual model: (a) S21 Results for both scenarios - Antenna (TX log periodic) at 2 meters where as the RX log periodic is placed at heights of 1 meter and 4 meters above the ground plane; (b) Measurement setup - Antennas (TX) and (RX)

Table III presents the measured and computed NSA of the two antennas log periodic in $650 \mathrm{MHz}$.

Table 3 Comparison of the measured and theoretical NSA results in $650 \mathrm{MHz}$ - Log Periodic Antenna

\begin{tabular}{lcc}
\hline & Measured NSA [dB] & Computed NSA [dB] \\
\hline RX antenna 1 meter height & -14.40 & $-13,00$ \\
RX antenna 4 meters height & $-16,81$ & -12.48
\end{tabular}

According to the results shown in the Table 3, a good correlation of the measured NSA and computed NSA is achieved at the frequency $650 \mathrm{MHz}$ (1 meter height). During the simulations, the NSA(dB) for the RX antenna at 4 meters is $-12.48 \mathrm{~dB}$, the measured NSA is -16.81. An important observation is that in the measurements, there was not used an ellipse with the calculated dimensions. We used a ground plane with dimensions of 1 meter by 3 meters, see Fig. 4a. A study of the behaviour of a setup using an elliptical ground plane should be done in the future for better understanding of the observed effects.

The difference between the computed and measured NSA is shown in Table III (for 1 meter and 4 meters height). It does not prevent the construction of OATS for the purpose of measuring the shielding effectiveness quality factor of cables and connectors, because the measured NSA value is close to the theoretical one [2, 8]. The Fig. 6a shows the computed NSA in dB (for 1 and 4 meters height) and Fig. $6 \mathrm{~b}$ the metal ellipse and two log periodic antennas used in the simulation model.

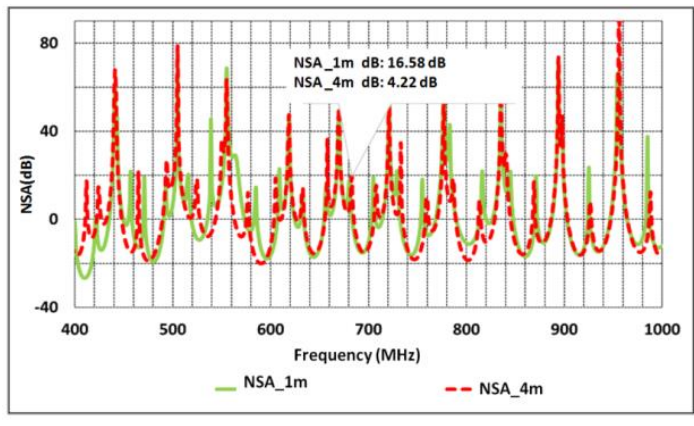

$a$

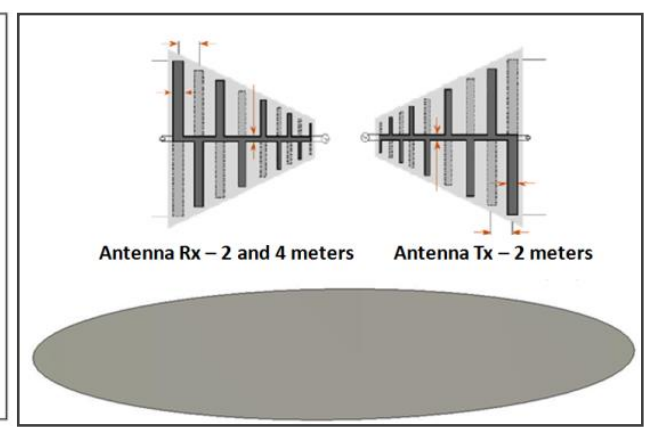

$b$

Fig. 6. The NSA computed and metal ellipse representing the OATS used in virtual model: (a) The NSA computed by CST; (b) Metal ellipse representing the OATS 


\section{THE EFFECT OF VARIABLE HEIGHT OF THE SETUP GROUND PLANE OVER THE CHAMBER GROUND PLANE}

In order to better understand the effects of the distance to the ground plane, related to the open site area, the setup of Fig. 7 was assembled. The measurement was carried out in a semi-anechoic chamber. The arrangement has been used with heights of zero (right on the floor) and 1 meter. The coaxial cable, named DUT, is tested as a source of EM waves, which leak through the imperfect shielding. Fig.7a shows a graphic of the setup and $7 \mathrm{~b}$ depicts a photo of the setup used in the semianechoic chamber [19].

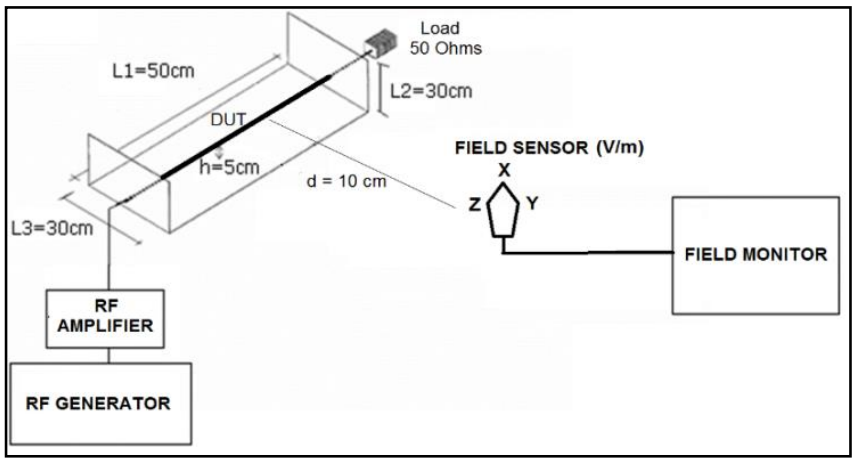

$a$

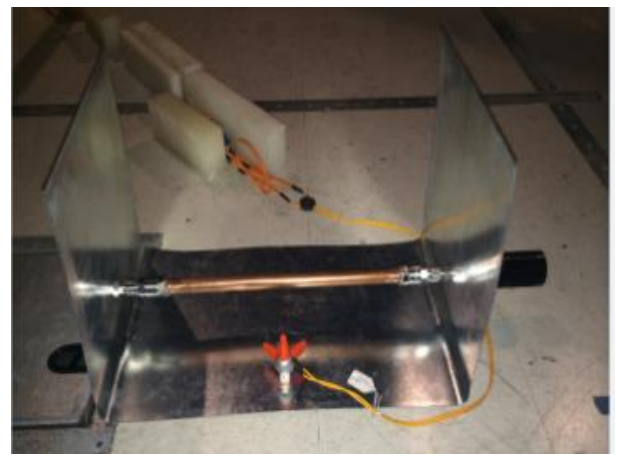

$b$

Fig. 7. Setup used to measure the Shield effectiveness quality of cables and connectors [2]: (a) Measurement setup graphic; (b) Measurement setup photo

The experimental arrangement is based on the following parameters (shown in Figure 7a): $\mathrm{L} 1=50 \mathrm{~cm}$, $\mathrm{L} 2=30 \mathrm{~cm}, \mathrm{~L} 3=30 \mathrm{~cm}, \mathrm{~h}=5 \mathrm{~cm}$ and load $=50 \Omega$. The distance between the electric field probe and the cable center has been set to $10 \mathrm{~cm}[2]$.

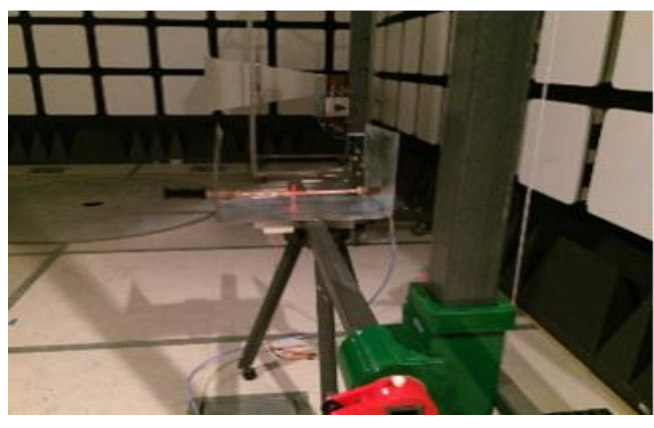

$a$

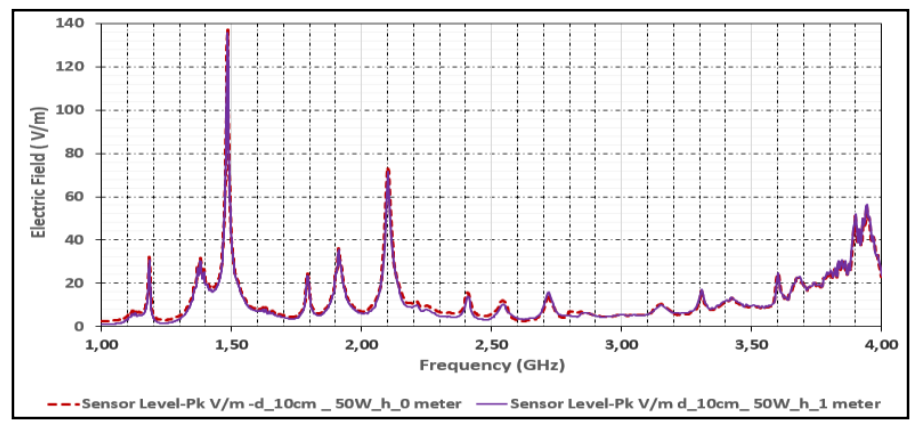

$b$

Fig. 8. Setup used to measure the shield effectiveness and results of electric field measurements with 50 Watts injected: (a) Measurement setup photo- 1 meter height; (b) Electric field measurements height zero meters versus one meter.

Figure 8a shows the setup above the ground plane of the chamber and the measured electrical signal level from $1 \mathrm{GHz}$ to $4 \mathrm{GHz}$. The power applied to the cable and connectors under test was 50 Watts for both cases, the arrangement with the height at zero meters and with the height of one meter. The cable was placed at $5 \mathrm{~cm}$ height above the setup ground plane, as illustrated in Figure 7a and as recommended by the CISPR 25 standard $[6,21]$. The goal is to simulate something physically very close to the real environment of a metallic vehicle chassis and conductors arranged above its surface $[21,22]$. 
It can be observed that there are no significant differences in the amplitudes of the measured signals for different heights, as Fig. $8 \mathrm{~b}$ shows. It was observed that small variations found in the measurements are not relevant in this frequency band considering that it is a microwave signal and that it is very directional. With the objective to evaluate the correlation in an impartial manner, the previous measures have been computed through the Feature Selective Validation algorithm [23, 24].

\section{CORRELATION THROUGH FEATURE SELECTIVE VALIDATION}

The Feature Selective Validation (FSV) technique may in general be used with any kind of input dataset (measurements, simulations, collections etc). The input vectors shall have the correspondent number of samples and are assumed consistently spaced versus the independent variable. The calculation is executed by means of FSV method that was introduced in IEEE Std. 1597.2 [24].

The Feature Selective Validation calculation is decomposed in three phases. In the first phase, the new datasets are preprocessed to extract the DC (zero frequency), low frequency and high-frequency parts that are fed to the second phase - Amplitude difference measure (ADM) and feature difference measure (FDM). The mixture of these two vectors (ADM and FDM) is a measure of the global difference, and represents the last phase (GDM).

The Amplitude Difference Measure (ADM) is given in equation (5), where $L o_{1}$ and $L o_{2}$ are the low pass filter components of the original data and $N$ is the total number of data points being considered.

$$
\operatorname{ADM}(n)=\left|\frac{\alpha}{\beta}\right|+\left|\frac{\chi}{\delta}\right| \exp \left\{\left|\frac{\chi}{\delta}\right|\right\}
$$

Where

$$
\begin{gathered}
\alpha=\left(\left|L o_{1}(n)\right|-\left|L o_{2}(n)\right|\right) \\
\beta=\frac{1}{N} \sum_{i=1}^{N}\left(\left|\mathrm{Lo}_{1}(\mathrm{i})\right|+\left|\mathrm{Lo}_{2}(\mathrm{i})\right|\right) \\
\chi=\left(\left|D C_{1}(n)\right|-\left|D C_{2}(n)\right|\right) \\
\delta=\frac{1}{N} \sum_{i=1}^{N}\left(\left|D C_{1}(i)\right|+\left|D C_{2}(i)\right|\right)
\end{gathered}
$$

The Feature Difference Measure (FDM) is computed from the normalized difference of a combination of derivatives of the band and high pass data. The FDM is given in equation 10 .

$$
F D M(n)=2\left(\left|F D M_{1}(n)+F D M_{2}(n)+F D M_{3}(n)\right|\right)
$$

Where

$$
\begin{aligned}
& F D M_{1}(n)=\frac{\left|L o_{1}{ }^{\prime}(n)\right|-\left|L o_{2}{ }^{\prime}(n)\right|}{\frac{2}{N} \sum_{i=1}^{N}\left(\left|L o_{1}{ }^{\prime}(i)\right|+\left|L o_{2}{ }^{\prime}(i)\right|\right)} \\
& F D M_{2}(n)=\frac{\left|H i_{1}{ }^{\prime}(n)\right|-\left|H i_{2}{ }^{\prime}(n)\right|}{\frac{6}{N} \sum_{i=1}^{N}\left(\left|H i_{1}{ }^{\prime}(i)\right|+\left|H i_{2}{ }^{\prime}(i)\right|\right)}
\end{aligned}
$$




$$
F D M_{3}(n)=\frac{\left|H i_{1} "(n)\right|-\left|H i_{2} "(n)\right|}{\frac{7.2}{N} \sum_{i=1}^{N}\left(\left|H i_{1} "(i)\right|+\left|H i_{2} "(i)\right|\right)}
$$

Combining the ADM and FDM gives a Global Difference Measure (GDM) (both as point-by-point and as an overall goodness-of-fit measure), according to equation 14. The IEEE 1597.2 standard requires categorizing feature selective validation index values with an interpretation scale as in Table $4[23,24]$.

$$
\operatorname{GDM}(n)=\sqrt{(A D M(n))^{2}+(F D M(n))^{2}}
$$

Table 4 Interpretation scale for feature selective validation indexes

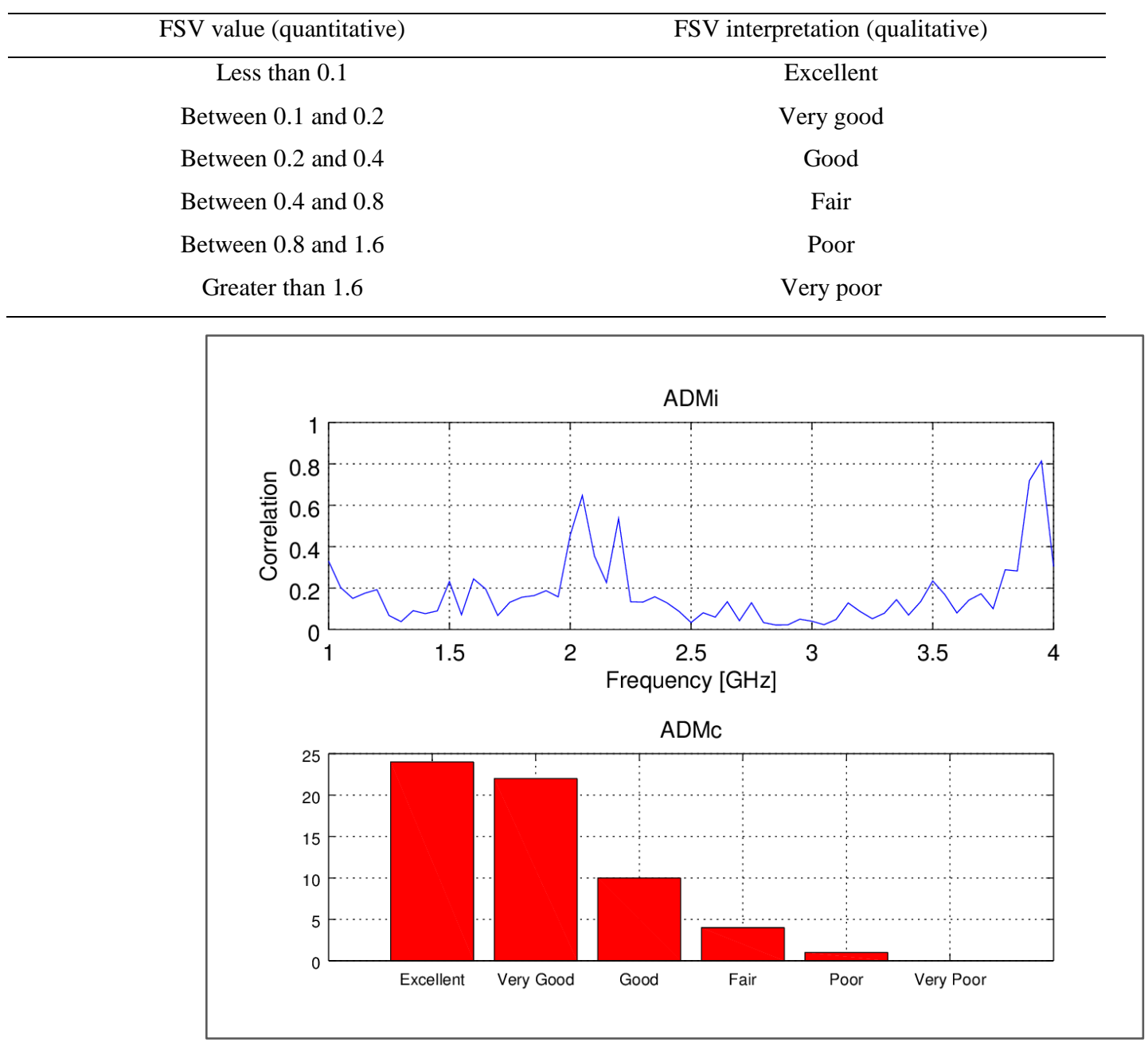

Fig. 9. Amplitude correlations between the measured electric fields

Fig. 9 and Fig. 10 shows an excellent amplitude and frequency correlations, the ADMi Average is 0.037 and the average value of FDMi is 0.096 . 


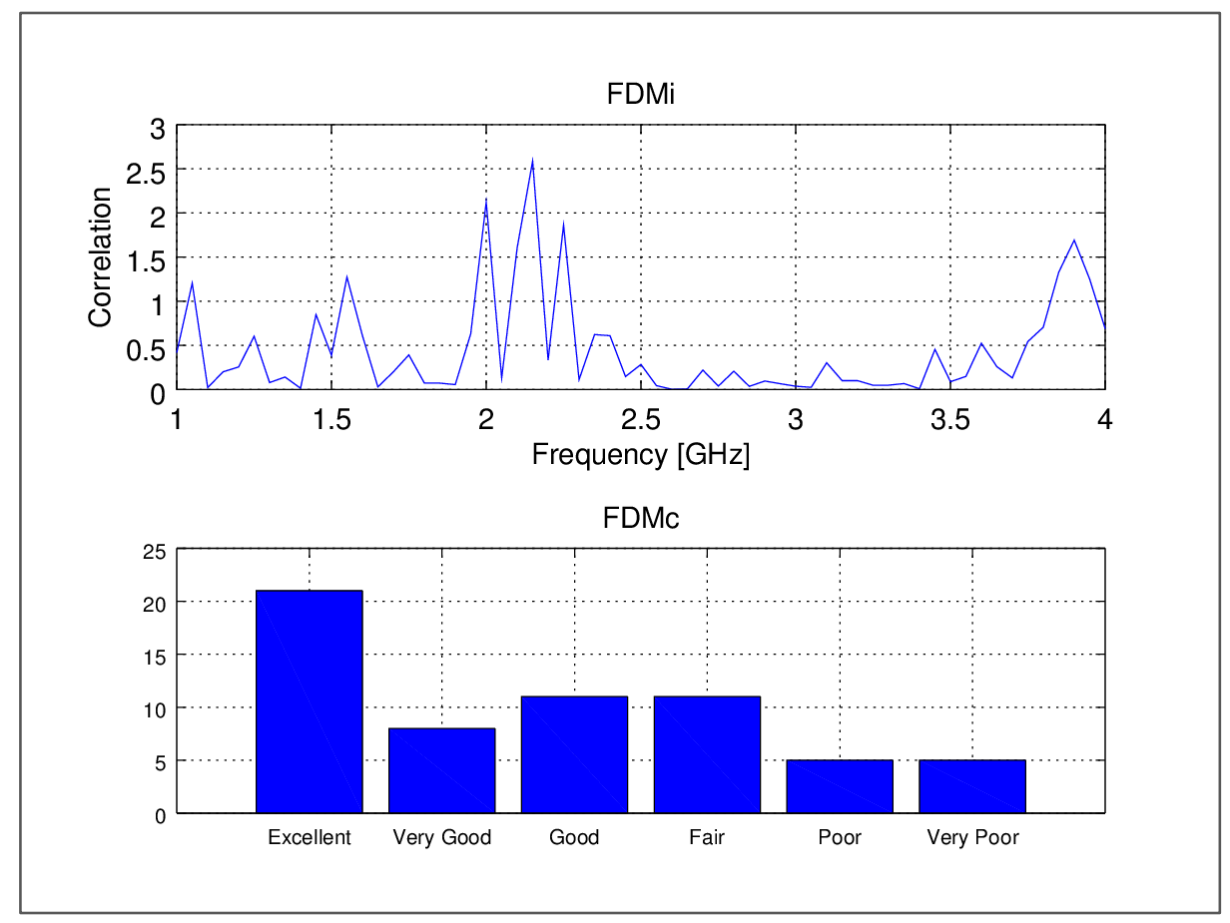

Fig. 10. Frequency correlations between the measured electric fields

Figure 11 shows the computed average GDMi of 0.109 (categorized as "Very good"), it can be seen that the electric field measurements at a height zero meters versus one meter did not show a significant variation. This analysis shows in addition that the ground plane dimensions are adequate for shielding effectiveness measurements.

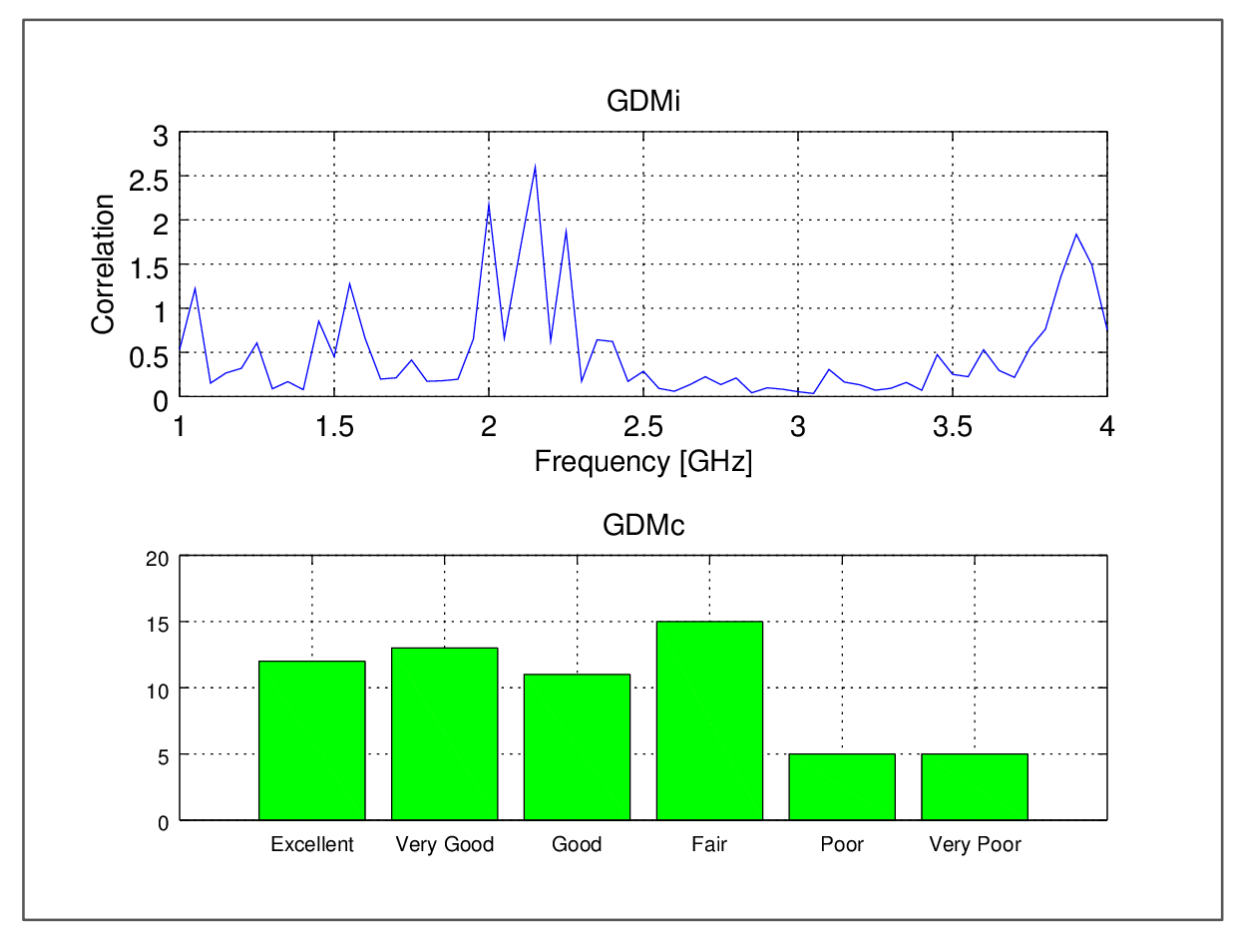

Fig. 11. Global correlations between the measured electric fields 


\section{CONCLUSION}

It can be concluded that the methodology presented here is efficient to analyze the frequency response in VHF and UHF band in an open area test site, if this analysis is carried out at a proper place and following the respective regulations. The problem encountered in ground plane simulation does not prevent the construction of OATS. The electromagnetic performance does not show high sensitivity to the different antenna heights used, which ensures a good testing repeatability as presented in the performed spectral analysis. The results of the research conducted in this article show that it is technically feasible to create a OATS for carrying out the quality factor measurements of coaxial cable shielding and connectors in the Farm located near the city of Capelinha, state Minas Gerais, Brazil (Lat. $17,8651^{\circ} \mathrm{S}-$ Long. $42,4313^{\circ} \mathrm{W}$ ).

Considering that the farm is located between mountains and that testing will be performed in the microwave range with power levels in the order of 1-10 Watts, there is no risk of electromagnetic interference with the neighboring towns. Table 1 showed the importance of measurements in the Open Area Test Site in the last years. If the Device Under Test (DUT) is large or heavy it is not possible to use regular laboratory for tests (e.g. semi and anechoic chambers).

The Semi-Anechoic Chamber which permits measurement of equipment emissions by excluding almost all external noise via ferrite absorber tiles, placed around the room, has a much higher cost of several million dollars for automotive EMC tests. The OATS facility is not very expensive with a cost of about five hundred thousand dollars

\section{ACKNOWLEDGMENTS}

The authors would like to thank SENAI CIMATEC in Salvador - BA, Brazil. Fiat Chrysler Automobiles (FCA) plant in Betim - MG, Brazil, for the use of its broadband antenna, receiver, spectrum analyser and Mr. José Maria Olimpio, the owner of the farm. CAPES/CNPq for the financial support and FAPESB doctoral scholarship.

\section{REFERENCES}

[1] PAUL, C.R, Introduction to Electromagnetic Compatibility, John Wiley \& Sons, Inc., New York, New York, 1992;

[2] Santos, K. M. G. et al. A Simple Test for Measuring the Shielding Effectiveness of Coaxial Cables and Connectors, International Journal of Applied Electromagnetics and Mechanics, DOI: 10.3233/JAE-170032, Vol.55, no.1, pp. 151-166, August 8, 2017.

[3] I. Echeverria; F. Arteche; M. Iglesias; A. Pradas; J. Piedrafita; F. J. Arcega, "Common Mode Noise Propagation and Effects in a Four-Wheel Drive Electric Vehicle," in IEEE Transactions on Electromagnetic Compatibility, vol.PP, no.99, pp.1-8, March 16, 2017.

[4] B. Démoulin, L. Koné, Shielded Cable Transfer Impedance Measurements in the Microwave Range of $1 \mathrm{GHz}$ to $10 \mathrm{GHz}$, IEEE-EMC Newsletter, Winter 2011, pp 52-61.

[5] CISPR 22: Edition 6.0 2008-09: Information technology equipment - Radio disturbance characteristics -Limits and methods of measurement.

[6] CISPR 25: Edition 4.0 2016-10: Vehicles, boats and internal combustion engines - Radio Disturbance Characteristics Limits and methods for the protection on board receiver.

[7] CISPR 16-1-4: Edition 3.2 2017-01: Specification for radio disturbance and immunity measuring apparatus and methods. 
[8] SANTOS, K. M. G. et al., Study On Technical Feasibility Of An Open Area Test Site In Brazil For The UHF Band (300 MHz to $1 \mathrm{GHz}$ ). In: SAE, 2014, São Paulo. Anais Congresso e Mostra Internacionais SAE BRASIL de Tecnologia da Mobilidade, São Paulo, 2014.

[9] S. Zhenfei, X. Ming, W. Fan, G. Xiaoxun and W. Weilong, "A phase-matching method for antenna phase center determination basing upon site insertion loss measurement in OATS," 2013 Proceedings of the International Symposium on Antennas \& Propagation, Nanjing, 2013, pp. 255-258.

[10] D. Qiao, Z. Qi, H. Mingliang and S. Dong-an, "Analysis of scattering property of open-area test site ground plane," 2014 XXXIth URSI General Assembly and Scientific Symposium (URSI GASS), Beijing, 2014, pp. 1-4.

[11] I. Barbary et al., "On the quality of a real open area test site," 2015 IEEE International Symposium on Electromagnetic Compatibility (EMC), Dresden, 2015, pp. 1201-1206.

[12] Donglin Meng, Xiao Liu and Dabo Li, "Research on unwanted reflections in an OATS for precise omni antenna measurement," 2015 IEEE 6th International Symposium on Microwave, Antenna, Propagation, and EMC Technologies (MAPE), Shanghai, 2015, pp. 245-249.

[13] W. Valente, A. Raizer and L. Pichon, "The Use of Equivalent Model and Numerical Simulation for EMC Analysis in Hospital Environments," in IEEE Transactions on Electromagnetic Compatibility, vol. 58, no. 4, pp. 950-955, Aug. 2016.

[14] D. Meng, "A Fast Way to Accurately Calibrate Tunable Dipole Antennas at VHF," in IEEE Transactions on Electromagnetic Compatibility, vol.PP, no.99, pp.1-10

[15] D. Qiao, Z. Qi, H. Mingliang and S. Dong-an, "Analysis of scattering property of open-area test site ground plane," 2014 XXXIth URSI General Assembly and Scientific Symposium (URSI GASS), Beijing, 2014, pp. 1-4.

[16] CST MICROWAVE STUDIO® - Overview -,“( 2015 CST Computer Simulation Technology AG. $",<$ https://www.cst.com/Applications/Category/Connectors $>, 25 / 03 / 2016$.

[17] A. M. Uribe-Leal; M. A. Muñoz; I. Garcia-Ruiz, Extended characterization of an open-area Antenna Calibration Test Site, Precision Electromagnetic Measurements Conference on CPEM, 2014.

[18] I. Barbary; L. O. Fichte; M. Stiemer; S. Lange; M. Schaarschmidt; R. Pape; T. Kleine-Ostmann; T. Schrader, On the quality of a real open area test site, IEEE International Symposium on Electromagnetic Compatibility(EMC), 2015.

[19] SANTOS, K. M. G. et al., Measurement of Shielding Effectiveness in Coaxial Cable Connectors Using an Electric Field Probe from $1 \mathrm{GHz}$ to $4 \mathrm{GHz}$, XVII International Symposium on Electromagnetic Fields in Mechatronics, Electrical and Electronic Engineering - ISEF 2015 Valencia, Spain, September 8, 2015.

[20] S. Park, M. Kotzev, H. D. D. Brüns, D. G. Kam and C. Schuster, "Lessons from applying IEEE standard 1597 for validation of computational electromagnetics computer modeling and simulations," in IEEE Electromagnetic Compatibility Magazine, vol. 6, no. 2, pp. 55-67, Second Quarter 2017.

[21] Braglia, Giacomo, Alistair Duffy, and Sami Barmada, Simulation Validation of Experimental Tests for Automotive System EMC Developmental Tests. Applied Computational Electromagnetics Society Journal

31.9 (2016).

[22] Ryszard Kopka et al. Metrological Properties of the Test Setup for Determination Shielding Effectiveness of the Industrial Cable Connectors, International Journal of Electronics and Telecommunications, vol. 63, no. 1, pp. 11-18, 2017.

[23] A. Colin, Perotoni, M. B., Santos, K. M.G., E. Ferreira, M. Andrade, S. Marchiori, M. Menezes, A. Nogueira, "Feature Selective Validation Analysis applied to Measurement and Simulation of Electronic Circuit Electromagnetic Emissions", Congress IEEE EMC Europe 2017, September 4-8, 2017, Angers, France (Paper accepted for publication).

[24] Recommended Practice for Validation of Computational Electromagnetics Computer Modeling and Simulations, IEEE Std. 1597.2, 2010. 